\title{
Conditioning of the pyramidal response in unanesthetized cats*
}

\author{
RICHARD A. ROEMER, TIMOTHY J. TEYLER, and RICHARD F. THOMPSON \\ Laboratory of Psychobiology, Department of Psychology and Social Relations \\ Harvard University, Cambridge, Massachusetts 02138
}

\begin{abstract}
The effect of a classical conditioning paradigm on the evoked pyramidal activity in immobilized cats was examined. The lower-frequency evoked pyramidal discharge appears to be a more robust measure of conditioning than is a criterion based upon axonal discharges recorded in the medullary pyramids. Conditioning was observed using either criterion.
\end{abstract}

The pericruciate cortical area (PCA) of cat includes much of the classically defined somatic sensory-motor and motor-sensory regions of the neocortex (Woolsey, 1958). In addition, PCA displays polysensory responses characteristic of association cortex (Thompson, Johnson, \& Hoopes, 1963; Teyler et al, 1974), and responses of single neurons in this region have been obtained to simple auditory, visual, and tactile stimuli (Buser \& Imbert, 1961; Brooks \& Stoney, 1971). A high percentage of cells of origin of the pyramidal tract (PTNs) are found in PCA (Weisendanger, 1969; Towe, 1973). These cells have similarly been shown to possess polysensory characteristics (Teyler, Roemer, \& Thompson, 1971; Chu \& Rutledge, 1971; Denney \& Thompson, 1967).

Rather discrete receptive properties have been reported for PCA neurons. PTNs, as well as unidentified PCA cells, have been shown to respond selectively to stimuli moving through the visual field (Teyler, Shaw, \& Thompson, 1972). Similar visual-receptive field properties have been described for cells of the association area lying on the middle suprasylvian gyrus of cat (Dow \& Dubner, 1969, 1971; Dubner \& Brown, 1968). Garcia-Rill and Dubrovsky (1973) report topographical organization of visual information in PCA. In general, a greater percentage of neurons with cutaneous receptive fields in the trunk and proximal body regions possessed visual receptive fields, compared to units in the distal regions. Neurons in PCA have also been shown to respond in a selective manner to auditory stimulation. Both PTNs and non-PTNs display tuning curves that are broader and less sensitive than those found in primary auditory cortex neurons (Teyler et al, 1974).

Analyses of somatosensory projections to neurons in PCA have shown receptive field characteristics whose properties seem to change after repeated tactile

*Supported in part by Equipment Grant 6B 14665 from the National Science Foundation, Research Grant 19314 from the National Institute of Mental Health, and Research Scientist Award MH 06650 from the National Institute of Mental Health to Richard F. Thompson), Predoctoral Fellowship MH 48912 from the National Institute of Mental Health (to Richard A. Roemer), and Postdoctoral Fellowship MH 35534 from the National Institute of Mental Health (to Timothy J. Teyler). stimulations or joint movements (Brooks, Rudomin, \& Slayman, 1961). This plastic characteristic of PCA units appears to differ from the receptive field properties of neurons in ventrobasal thalamus (Poggio \& Mountcastle, 1963). These contrasting observations suggest that significant integration may occur in pericruciate cortex. Modification of PCA unit activity by operant (Fetz, 1969; Fetz \& Finocchio, 1971) and classical (O'Brien \& Fox, $1969 \mathrm{a}, \mathrm{b})$ procedures lend support to this hypothesis. Consistent with this observation of plasticity in PCA units are studies describing the role of the pyramidal system during performance of a well-learned task (Evarts, 1969) and during habituation to a tactile stimulus (Teyler, Roemer, \& Thompson, 1972).

The emergent evidence of functional polysensory convergence on PT cells, in conjection with pyramidal system involvement in motor control (Brooks \& Stoney, 1971) and demonstrated plasticity in PCA, make the pyramidal system an attractive candidate for studies on the neural bases of learning. This study is a report of attempts at classically conditioning the pyramidal tract activity in immobilized cats. Previous studies have shown that immobilized animals are capable of modifying autonomic activity under classical (Black, 1965) and instrumental (Miller, 1969) paradigms. We hypothesized that immobilized animals would be also able to modify activity in the pyramidal tract as a function of stimulus contingencies.

\section{EXPERIMENT I}

Experiment I involved training immobilized unanesthetized cats in a paradigm analogous to classical forelimb-flexion conditioning. The dependent variable was the pyramidal tract response recorded at the level of the medulla. Ss were exposed to a series of forward pairings of CS and US presentations and a series of explicitly unpaired CS and US presentations.

\footnotetext{
Method

Five cats were used in this experiment; all were surgically prepared under ether anesthesia while mounted in a standard stereotaxic apparatus. Two brain exposures were made: one over
} 


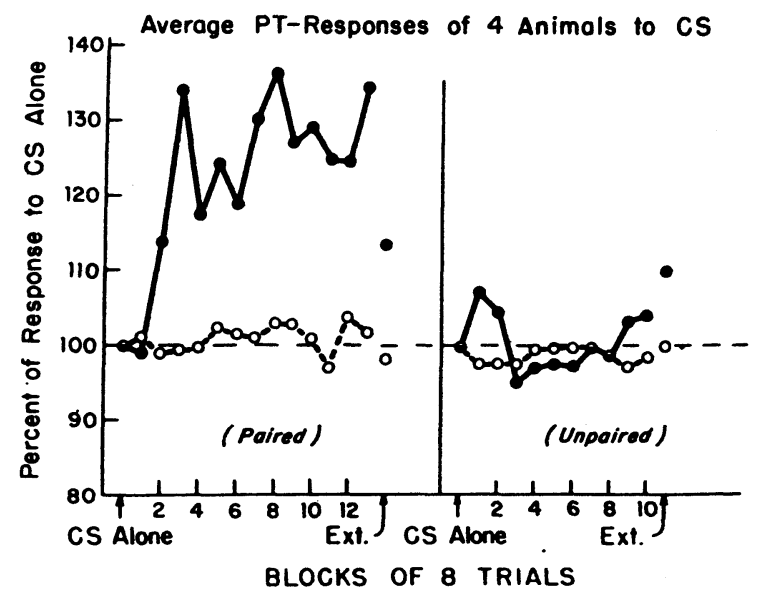

Fig. 1. Averaged, rectified, and integrated pyramidal tract activity relative to the initial CS-alone trials. Open circles indicate pre-CS activity; closed circles indicate activity during CS period.

the pericruciate association area of cortex, the other a 5- to 7-mm opening over the cerebellum at P10. A concentric bipolar recording electrode was introduced through this latter opening. Positioning of the recording electrode was accomplished by transdurally stimulating PCA with $15-$ to $30-\mathrm{V}, 0.1-\mathrm{msec}$ bipolar pulses in the forepaw region of the ipsilateral motor cortex and recording short-latency $D$ and $I$ waves in the pyramidal tract with the concentric electrode. These evoked volleys, in conjunction with the absence of short-latency click-evoked responses, electrophysiologically confirmed the placement of the concentric recording electrode in the medullary pyramidal tract. This electrode was then positioned to obtain the maximum-amplitude volley to $15-$ to $30-\mathrm{V}, 0.1-\mathrm{msec}$ shocks applied to the contralateral forepaw and secured in place with dental acrylic.

The animal was then suspended atraumatically (Teyler \& Biela, 1971), and cut-tissue margins and pressure points were infiltrated with Zyljectin. Discontinuation of ether was followed by induction of paralysis by Flaxedil and the introduction of artificial respiration. Ss were maintained in a paralytic state by the continuous administration of Flaxedil IV (about $10 \mathrm{mg} / \mathrm{h}$ ). That the preparation was atraumatic was demonstrated by: (1) pupillary constriction and (2) sleep-spindles in the EEG after prolonged absence of peripheral stimulation. After a time lapse of 2 to $3 \mathrm{~h}$, to permit stabilization of the $\mathrm{S}$, the conditioning phase was begun. A $1-, 2-, 4-$, or $10-\mathrm{kHz}$ tone, equated for intensity, was used as the CS with a $2-\mathrm{mA}, 60-\mathrm{Hz}$ contralateral forepaw shock as the US.

Following $16 \mathrm{CS}$-alone presentations, Ss were exposed to two procedures with a random order of presentation. One procedure consisted of 96 randomly distributed paired CS-US presentations with a mean intertrial interval of $60 \mathrm{sec}$ and a range from 40 to $80 \mathrm{sec}$. The CS was $1.78 \mathrm{sec}$ in duration, the last $500 \mathrm{msec}$ being coincident and coterminus with the US. The other procedure consisted of 96 explicitly unpaired presentations of one of the remaining CS tones and the same US, with stimulus durations the same as during pairing. At the conclusion of one of the two randomly selected procedures, and following a 1-h extinction period, the remaining procedure was employed.

The dependent variable in this study was the gross evoked pyramidal activity recorded during a 1.28 -sec pre-CS period and the first $1.28 \mathrm{sec}$ of the CS period. Data were generally not collected during the US period because of shock artifacts.
Computer-averaged pre-CS and CS waveforms were obtained for every set of eight consecutive CS presentations. Therefore, 2 averages were obtained for the CS-alone periods and 12 averages were obtained for the paired or unpaired trial periods, followed by 1 or 2 averages obtained during extinction.

Two steps were involved in the analysis of the experimental data. First, based upon previous analyses of evoked pyramidal activity (Teyler, Roemer, \& Thompson, 1972) we defined the averaged, rectified, and integrated evoked pyramidal activity recorded during the pre-CS and CS period of the first eight CS-alone presentations as $100 \%$ response. Subsequent averages for each successive eight trials were rectified and integrated and each time period, pre-CS and CS, expressed as a percent of the respective CS-alone response level. Second, the 15 averaged waveforms were plotted with hidden line suppression via the PDP-12 computer.

\section{Results}

Figure 1 shows the rectified and integrated pyramidal tract activity averaged over four Ss. The solid circles reflect the relative pyramidal tract activity during the CS period, in both the paired and unpaired procedures, while the open circles indicate the relative activity during the corresponding pre-CS periods.

An example of the rapidity with which CS-US pairing elicits responses within the CS period is shown in Fig. 2. The first two records (Fig. 2A, bottom) show the pyramidal tract activity of the pre-CS and CS periods during CS-alone presentations. The solid triangle
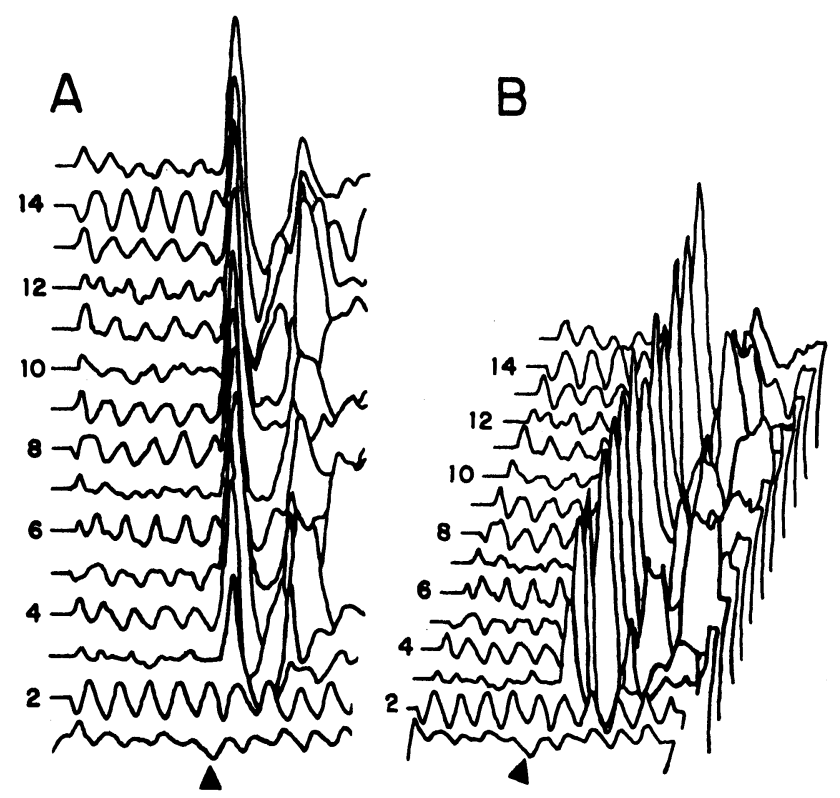

Fig. 2. Progressive development of pyramidal response during CS-US pairing. Each trace (1-15) is the average response for eight trials. Trial Averages 1 and 2 indicate activity during CS-alone presentations. Solid triangle indicates CS onset. Figure $2 \mathrm{~A}$ shows pre-CS activity and first component of CS response. Figure 2B permits inspection of secondary response component. Positive is up in this and all following figures. Sweep duration in Figs. 2 and 3 is 2.56 sec. 
indicates CS onset. The third record represents the beginning of CS-US pairing. A rapid and striking increase in response to the CS onset is observed in the third average. A late response, occurring just preceding US onset, is seen-developing in Average 4, and appearing in all following averages. Figures $2 \mathrm{~A}$ and $2 \mathrm{~B}$ present the same data. The isometric projection of Fig. $2 \mathrm{~B}$ permits a clearer view of the development of the later response.

An additional animal was used to evaluate the possibility of order effects and to demonstrate the applicability of the pyramidal preparation under a differential conditioning paradigm. Animal preparation, procedures, and data analysis were as described above, with the following exceptions: a differential paradigm was employed with a $10-\mathrm{kHz}$ tone and a $1.1-\mathrm{kHz}$ tone as the conditioned stimuli. Each tone was presented 144 times in a randomized order. In the first series of trials, the $\mathrm{CS}+$ was $10 \mathrm{kHz}$ and the US always followed its presentation. The $1.1-\mathrm{kHz}$ tone was the $\mathrm{CS}-$ and was never followed by the US. After training and extinction, the contingencies to the two tones were reversed and training was resumed.

Figure 3 indicates the results of differential training and $\mathrm{CS}$ reversal. Figures $\mathrm{BA}$ and $3 \mathrm{~B}$ show the pyramidal tract response to the $\mathrm{CS}+$ and to the $\mathrm{CS}-$, respectively. Note the evoked activity to the CS- during the CS-alone presentations. The first trial sequence (Averages 3 and following of Fig. 3A) reveals a developing positive response to the CS+ onset, followed by a late decrease. This is contrasted with average responses to the CS(Fig. 3B) during the same series. Here, the response to CS - onset changes little over trials and no consistent late negativity is observed.

The results of reversing the US contingencies associated with the two CS tones are shown in Fig. 3C and Fig. 3D. In this case, the $1.1-\mathrm{kHz}$ tone, formerly the $\mathrm{CS}-$, now becomes the $\mathrm{CS}+$, while the $10-\mathrm{kHz}$ tone is now the $\mathrm{CS}-$.

Figure 3C shows the development, to the new CS+, of an early positive deflection followed by a late negativity reminiscent of that observed in Fig. 3A. Figure 3D depicts pyramidal tract evoked activity to the new CS-. Here, the late negative response, seen when this tone was the CS+, is greatly attenuated. However, the continued observability of this response, the fact that it developed during previous pairing, and the changes of responses to $1.1 \mathrm{kHz}$ demonstrate a rather significant order effect of training procedures on this dependent variable.

\section{EXPERIMENT II}

Experiment II was identical to Experiment I, with the exception that the animals were trained under a differential paradigm. The evoked pyramidal activity was high-pass filtered and the pyramidal tract fiber potentials were summed as an index of conditioning. It was felt that this procedure might be more sensitive to rapid changes in the animals' responses to the conditioning stimuli.

\section{Method}

Thirteen cats were used in this experiment. Animal preparation and procedures were as in the latter part of Experiment I, with CS+ and CS - tones randomly assigned. There was no differential reversal. The data were high-pass filtered $(500-10,000 \mathrm{~Hz})$ and preprocessed by a Schmidt trigger comparator (Cegavske, Roemer, \& McCurnin, 1973) adjusted to pass 300 to 500 counts/sec. The Schmidt-triggered fiber potentials were counted over a 1.28 -sec pre-CS period and a 1.28 -sec CS period. A difference score was calculated by subtracting the pre-CS period total from the CS period total. These difference scores were averaged in blocks of eight across the $72 \mathrm{CS}+$ and $72 \mathrm{CS}-$ acquisition trials and referenced to CS-alone activity levels.
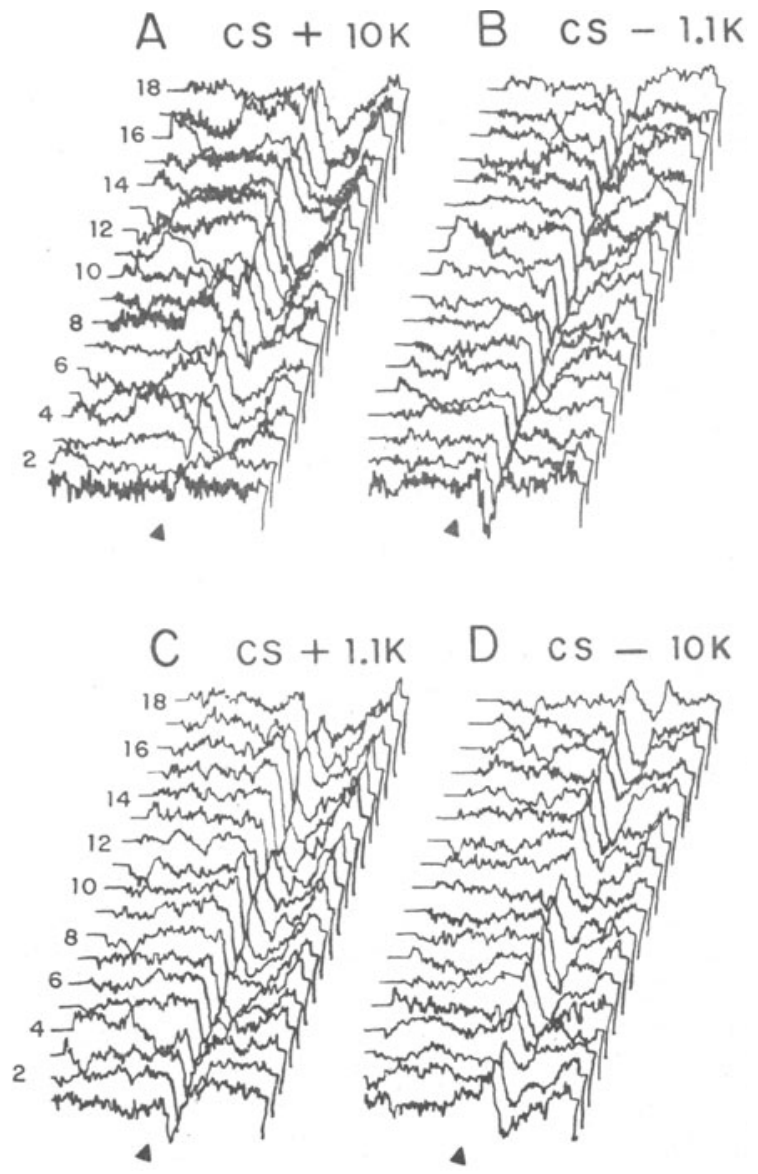

Fig. 3. Pyramidal responses during differential classical conditioning for an individual S. Figure $3 \mathrm{~A}$ shows pre-CS and CS responses to a $10-\mathrm{KHz} \mathrm{CS}+$, while Fig. 3B shows pre-CS and $\mathrm{CS}-$ responses to a 1.1-kHz CS-. Figures $3 \mathrm{C}$ and $3 \mathrm{D}$ show averaged pyramidal responses when the CS-US contingencies were reversed. Solid triangles indicate CS onset. Each trace (1-18) reflects average response for eight consecutive trials. Note development of late negative response to both $\mathrm{CS}+$ presentations. 


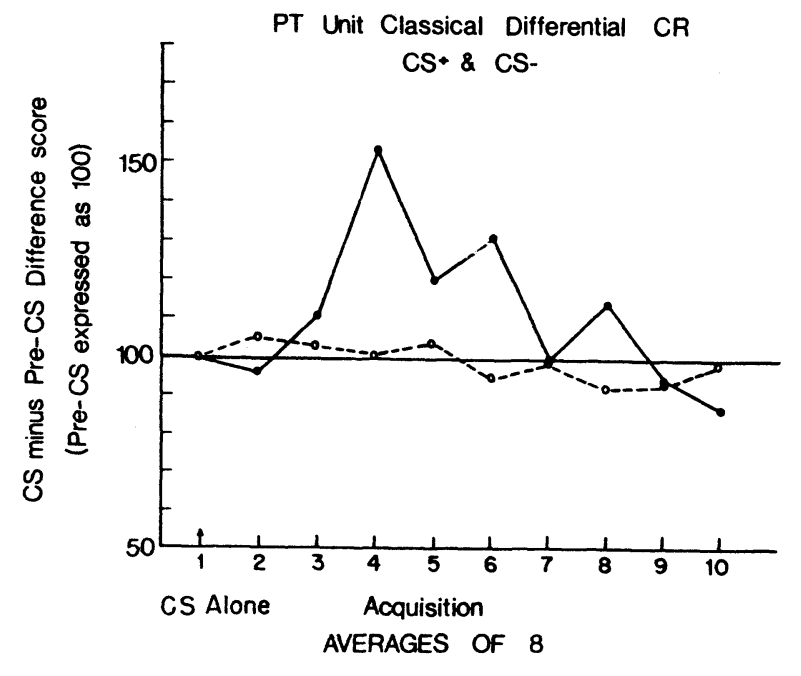

Fig. 4. Average CS - pre-CS difference scores for 13 Ss during acquisition trials. Closed circles indicate CS+ difference scores; open circles indicate $\mathrm{CS}$ - difference scores.

\section{Results}

Figure 4 presents the average difference scores for all Ss during acquisition for both $\mathrm{CS}+$ and $\mathrm{CS}-$. An augmented response is seen to develop to the CS+ during the second block of acquisition trials. This response reaches a maximum on the third trial block, whereupon it subsequently declines. The response to the CS- is negligible. The CS+ data were parcelled into two extreme groups, those that clearly evidenced conditioned changes $(\mathrm{N}=3)$ and those that clearly did not $(\mathrm{N}=4)$. Figure 5 depicts these two groups of animals. The apparent decline in response magnitude seen in Fig. 4 probably represents the summation of data from animals that showed conditioning and animals that did not.

\section{Discussion}

These experiments indicate that the evoked pyramidal discharge in paralyzed cat can be classically conditioned and that the effect is similar to intact classical conditioning. The somewhat inconsistent results of Experiment II are actually in agreement with behavioral studies in showing less than robust conditioning, using a classical paradigm with footshock US.

Brodgen, Lipman, and Culler (1938) trained guinea pigs in an activity wheel under classical or instrumental avoidance CS-US contingencies. They found the development of a stable $100 \%$ anticipation rate under the instrumental approach and an unstable 35\% to $65 \%$ anticipation rate under the classical contingency. Rather similar results have been reported by Wahlsten and Cole (1972) and by Cassady (1972), using dogs in a classical and instrumental avoidance leg-flexion task. Under the classical procedure, they find, respectively, 50\% and 60\% anticipatory conditioned responses (CRs). Conversely, under the instrumental procedure, both studies report in excess of $90 \%$ anticipatory responses.
A striking fact, in the first experiment, is the rapidity of acquisition. This is similar to the acquisition of a conditioned response in the acute spinal cat (Patterson, Cegavske, \& Thompson, 1973). The speed of acquisition may reflect the fact that competing responses are unavailable to the Ss, since they are immobilized. In such a case (immobilization), effects of stimulus presentation are not altered by middle ear muscle contraction or movement of pinnae or the body. In addition, the S has no opportunity to "attend" to alternative stimuli in the environment, since extraneous auditory and visual stimuli have been largely eliminated from the sound-attenuated experimental room. The limited range of responses available to the $\mathrm{S}$ may also contribute to this rapid rate of acquisition.

In a previous study (Teyler, Roemer, \& Thompson, $1972)$, we reported a late (100-250-msec poststimulus) component of the evoked pyramidal discharge habituation paradigm. Interestingly, the late response seen in Fig. 2 and the late response to the CS+ in Fig. 3 begin in this same poststimulus onset time period. This raises the possibility that the similar latency of the evoked pyramidal discharge seen under two different testing situations reflects a common neuronal mechanism operative during sensitization and conditioning.

Current evidence suggests a functional dichotomy between slow and fast conducting pyramidal cells (Evarts, 1965; Naito et al, 1969; Kitai et al, 1969; Takahashi, 1965; Towe, 1974). Evarts (1965) has shown fast conducting PTNs to discharge in conjunction with wrist movement, while slow conducting PTNs were shown to stop discharging during these movements. This leads to the suggestion that the slow conducting PTN:

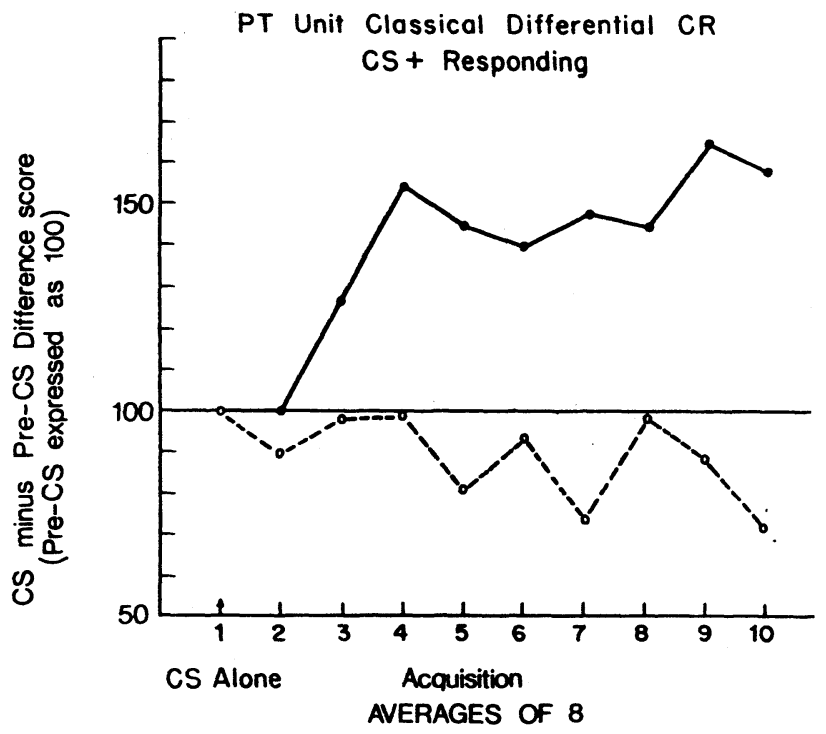

Fig. 5. Average CS - pre-CS difference scores for $\mathrm{Ss}(\mathrm{N}=7)$ demonstrating consistent differential response. Closed circles indicate CS+ difference scores, open circles indicate CSdifference scores. 
may be involved in "biasing" the motoneurons via interneurons, while the fast conducting PTNs "modulate" the motor system from the resultant bias level. In a previous report from our laboratory (Teyler, Roemer, \& Thompson, 1971), close examination of one of the figures presented (Fig. 1) indicates that the amplitude of cortically recorded extracellular spikes may be larger for the fast conducting PTNs. To our knowledge, a systematic analysis of extracellularly recorded amplitude and conduction velocity has not been reported for the PT system. If the slower PTNs exhibit smaller amplitude discharges than do the faster PTNs, the use of an amplitude criterion for the detection of discharges would tend to systematically select the faster conducting PTNs.

We reanalyzed the RPD and the multiple-axon discharges of one $\mathrm{S}$, systematically varying the amplitude criterion. Table 1 shows the correlation between the rectified RPD and the detected fiber potentials as a function of amplitude criterion. The amplitude criterion was defined by the number of counts/second as detected by the Schmidt trigger. Note that the criterion which selects the largest number of counts $(0<N<2,400)$ has a highly significant and positive correlation with the rectified RPD. Conversely, the criterion which selects the smaller number of counts $(0<\mathrm{N}<300)$ reflects a highly significant and negative correlation. As the criterion level is raised to select a smaller number of counts/second, the correlation values systematically fluctuate between positive and negative. This systematic fluctuation is not likely to be due to the instrumentation, since the computer and Schmidt trigger system have a bandwidth as wide as the amplifiers. The amplitude criterion used in Experiment II was in the range which could tend to result in a small positive correlation with the rectified RPD. The criterion was a count of between 300 and 500 discharges/sec. While there may be great inter-S variability, this criterion was in the range which, in the single $\mathrm{S}$ reported here, represented a transition from a highly negative to a highly positive correlation with the rectified RPD, i.e., a low correlation value. The apparently inconsistent results of Experiment II appear due, in part, to the use of an amplitude criterion only minimally correlated with the RPD.

The data presented here demonstrate classical conditioning of the pyramidal response in the immobilized cat. The preparation, as reported, is a promising one for the analysis of brain mechanisms of learning. A clearer understanding of the relationship between axon discharges and the RPD would make the approach even more attractive. Paralyzed cats clearly have the ability to contingently alter pyramidal motor-system activity. These plastic responses to repeated stimulus configurations may be intrinsic to the pyramidal motor system or may originate elsewhere. In
Table 1

Correlation Between Rectified RPD and Multiple Axon Discharges Recorded in the Medullary Pyramids as a Function of Discharges Per Second

\begin{tabular}{lcr}
\hline $\begin{array}{c}\text { Range of } \\
\text { Counts/Sec }\end{array}$ & $\begin{array}{c}\text { Correlation } \\
\text { Coefficient }\end{array}$ & $\begin{array}{c}\mathrm{t} \text { Test } \\
(\mathrm{df}=126)\end{array}$ \\
\hline $0<\mathrm{N}<2400$ & .85 & 18.95 \\
$0<\mathrm{N}<1600$ & -.71 & -11.63 \\
$0<\mathrm{N}<1150$ & .48 & 6.33 \\
$300<\mathrm{N}<850$ & .49 & 6.41 \\
$0<\mathrm{N}<300$ & -.66 & -10.03 \\
\hline
\end{tabular}

Note-All $t$ scores are significant at the $p<.01$ level.

any event, they represent a neural measure of behavioral plasticity which may provide a reference point for more central analyses of the neuronal mechanisms of behavioral plasticity.

\section{REFERENCES}

Black, A. H. Cardiac conditioning in curarized dogs: The relationship between heart rate and skeletal behavior. In W. F. Prokasy (Ed.), Classical conditioning: $A$ symposium. New York: A ppleton-Century-Crofts, 1965.

Brogden, W. J., Lipman, E. A., \& Culler, E. The role of incentive in conditioning and extinction. Journal of Experimental Psychology, 1938, 51, 109-117.

Brooks, V. A., Rudomin, P., \& Slayman, C. L. Sensory activation of neurons in the cat's cerebral cortex. Journal of Neurophysiology, 1961, 24, 286-301.

Brooks, V. B., \& Stoney, S. D. Motor mechanisms: The role of the pyramidal system in motor control. Annual Review of Physiology, 1971, 33, 337-392.

Buser, P., \& Imbert, M. Sensory projections to the motor cortex in cats: A microelectrode study. In W. A. Rosenblith (Ed.), Sensory communication. New York: Wiley, 1961.

Cassady, M. Neural correlates of avoidance and classical behavior. Unpublished doctoral dissertation, University of California at Irvine, 1972

Cegavske, C. F., Roemer, R. A., \& McCurnin, T. W. A low-cost integrated circuit comparator system. Behavior Research Methods \& Instrumentation, 1973, 5, 428-430.

$\mathrm{Chu}$, N., \& R utledge, L. T. Multisensory activation of pyramidal tract neurons in the cat. Experimental Neurology, 1971, 30, 352-361.

Denney, D., \& Thompson, R. F. Relationship between association response and activity in the pyramidal tract. Electroencephalography \& Clinical Neurophysiology, 1967, 23, 248-255.

Dow, B. M., \& Dubner, R. Visual receptive fields and responses to movement in an association area of cat cerebral cortex. Journal of Neurophysiology, 1969, 32, 773-784.

Dow, B. M., \& Dubner, R. Single-unit responses to moving visual stimuli in middle suprasylvian gyrus of the cat. Journal of Neurophysiology, 1971, 34, 47-55.

Dubner, R., \& Brown, F. J. Response of cells to restricted visual stimuli in an association area of cat cerebral cortex. Experimental Neurology, 1968. 20, 70-86.

Evarts, E. V. Activity of pyramidal tract neurons during postural fixation. Journal of Neurophysiology, 1965, 32, 375-385.

Fetz, E. E. Operant conditioning of cortical unit activity. Science, $1969,163,955-958$.

Fetz, E. E. \& Finochio, D. V. Operant conditioning of specific patterns of neural and muscular activity. Science, 1971, 174, 431-435.

Garcia-Rill, E., \& Dubrovsky, B. Topographical organization of visual input to precruciate cortex of cat. Brain Research, 1973, 56, 151-163.

Kitai, S. T., Oshima, T., Provini, L., \& Tsukahara, N. Cerebro-cerebellar connections mediated by fast and slow conducting pyramidal tract fibers of the cat. Brain Research, $1969,15,267-271$.

Miller, N. E. Learning of visceral and glandular responses. Science, 1969, 163, 434-445.

Naito, H., Nakamura, K., Kurosaki, T., \& Tamura, Y. Precise location of fast and slow pyramidal tract cells in cat sensori-motor cortex. Brain Research, 1969, 14, 237-239. 
O'Brien, J. H., \& Fox, S. S. Single-cell activity in cat motor cortex. I. Modifications during classical conditioning procedures. Journal of Neurophysiology, 1969a, 32, 267-284.

O'Brien, J. H., \& Fox, S. S. Single-cell activity in cat motor cortex. II. Functional characteristics of the cell related to conditioning changes. Journal of Neurophysiology, 1969b, 32, 285-296.

Patterson, M. M., Cegavske, C. C., \& Thompson, R. F. Spinal conditioning. Bulletin of the Psychonomic Society, 1973, 1 , 139-140.

Poggio, G. F., \& Mountcastle, V. B. The functional properties of ventrobasal thalamic neurons studied in unanesthetized monkeys. Journal of Neurophysiology, 1963, 26, 775-806.

Takahashi, K. Slow and fast groups of pyramidal tract cells and their respective membrane properties. Journal of Neurophysiology, 1965, 28, 908-924.

Teyler, T. J., \& Biela, J. An acute atraumatic stereotoxic headholder for cats. Physiology \& Behavior, $1972,8,543$.

Teyler, T. J., Roemer, R. A., \& Thompson, R. F. Relations between gross and unit evoked activity in pericruciate cortex of cat. Physiology \& Behavior, 1971, 6, 375-379.

Teyler, T. J., Roemer, R. A., \& Thompson, R. F. Habituation of the pyramidal response in unanesthetized cat. Physiology \& Behavior, 1972, 8, 201-205.

Teyler, T. J., Roemer, R. A., Wheeler, W., Metzler, J. \& Thompson, R. F. The pyramidal motor system: A site of sensory-motor integration. In: The neurophysiologic basis of rehabilitation medicine. Irvine: UCI Press, 1974. (In press).
Teyler, T. J., Shaw, C., \& Thompson, R. F. Unit responses to moving stimuli in the motor cortex of the cat. Science, 1972 , 176, 811-813.

Thompson, R. F., Johnson, R. H., \& Hoopes, J. J. Organization of auditory, somatic sensory, and visual projection to association fields of cerebral cortex in the cat. Journal of Neuro physiology, 1963, 26, 343-364.

Towe, A. L. Motor cortex and the pyramidal system In Efferent organization and the integration of behavior. New York: Academic Press, 1973.

Wahlsten, D. L., \& Cole, M. Classical and avoidance leg flexion in the dog. In A. H. Black and W. F. Prokasy (Eds.), Classical conditioning II: Current theory and research. New York: Appleton-Century-Crofts, 1972.

Wiesendanger, $M$. The pyramidal tract: Recent investigations on its morphology and function. Ergebnisse der Physiologie, $1969,61,72-136$.

Woolsey, C. N. Organization of somatic sensory and motor areas of the cerebral cortex. In H. F. Harlow and C. N. Woolsey (Eds.), Biological and biochemical bases of behavior. Madison Wisconsin: University of Wisconsin Press, 1958.

(Received for publication June 18, 1974; accepted June 27, 1974.) 